\title{
Ralstonia solanacearum Virulence in Cotyledon Stage Tomato Seedlings
}

ISSN: 2637-7659

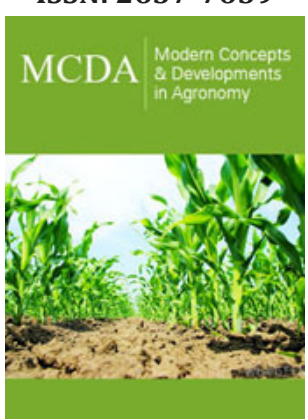

*Corresponding author: Ray SK, Department of Molecular Biology and Biotechnology, Tezpur University, Tezpur-784028, Assam, India

Submission: 眥July 12, 2020

Published: 監October 16, 2020

Volume 7 - Issue 3

How to cite this article: Kabyashree $\mathrm{K}$, Ray SK. Ralstonia solanacearum Virulence in Cotyledon Stage Tomato Seedlings. Mod Concep Dev Agrono. 7(3). MCDA. 000664. 2020. DOI: 10.31031/MCDA.2020.07.000664

Copyright@ Ray SK, This article is distributed under the terms of the Creative Commons Attribution 4.0 International License, which permits unrestricted use and redistribution provided that the original author and source are credited.

\section{Kabyashree K and Ray SK*}

Department of Molecular Biology and Biotechnology, Tezpur University, Tezpur-784028, Assam, India

\section{Abstract}

Ralstonia solanacearum causes a lethal bacterial wilt in more than 400 plant species that includes several agronomically important crops such as tomato, eggplant, potato, etc. Usually grown up tomato plants are used as model host to study its virulence functions. Recently we have demonstrated that cotyledon stage seedlings of tomato as well as eggplant can be used to study R. solanacearumvirulence functions. In this review we are summarizing our recent understanding of R. solanacearumpathogenicity by using seedlings as model host.

Keywords: Ralstonia solanacearum; Bacterial wilt; Plant pathogenic bacteria;Seedlings

\section{Introduction}

Bacterial wilt, caused by Ralstonia solanacearum, is a threat to many economically important crop plants such as tomato, potato, eggplant, olive, banana, peanut, ginger, etc. $[1,2]$. Moreover, it can also infect tree plants such as cashew, custard apple, sunflower, eucalyptus etc [3-6]. Owing to its severity, it has been ranked the second most devastating phytopathogenic bacterium in the world [7]. The bacterium is exceptionally versatile as it can survive either as saprophyte in soil for a long period or as a pathogen in susceptible host; also, it can inhabit plants as endophytes without causing disease $[2,8]$. Thus, the pathogen acquires a tight regulation of its metabolic and pathogenicity factors through two-component sensory and regulatory network maintaining a balance between its various regulators at different niches [8-10].

Much of the virulence functions of this bacterium have been characterized by inoculating in grown up tomato plants [11]. In spite of our much progress in understanding the pathogenomics of this model plant pathogenic bacterium, several interesting facts regarding its pathogenicity could not be revealed using the grown-up tomato plants as model host. Some of the questions are as follows:

(i) it is well known that R. solanacearum is a systemic pathogen that enter the host through the root and colonizes the entire plant before wilting it. It is interesting that the disease symptoms is prominent in the shoot but not in the root.

(ii) Though the infection starts from the root, wilting symptom initiates at the shoot apical region and then gradually move downwards.

(iii) The pathogen has a wide host range. How does the pathogen survive inside so many wide varieties of plants?

(iv) It is a vascular pathogen. The host xylem also houses several other endophytes. Do these endophytes influence the disease caused by $R$. solanacearum.

Cotyledon stage seedling is a promising system to study the virulence of $R$. solanacearum. The advantage of using seedlings is the minimalistic interaction with other micro-organisms. The use of seedlings allows scoring the disease in a more accurate form as a large number of seedlings can be recruited for virulence study. The seedlings of tomato and eggplant can be inoculated by the pathogen either in the leaf $[12,13]$ or in the root [14] to study its pathogenicity. The disease phenotype in seedling is observed within three days after inoculation. The 
whole experiment starting from seed germination, inoculation and disease scoring can be completed in two weeks period (Figure 1). The pathogen localization in the host can be studied by appropriate staining of the entire seedling [15]. Recently, bio control against $R$. solanacearum infection has been done using seedlings [16,17].

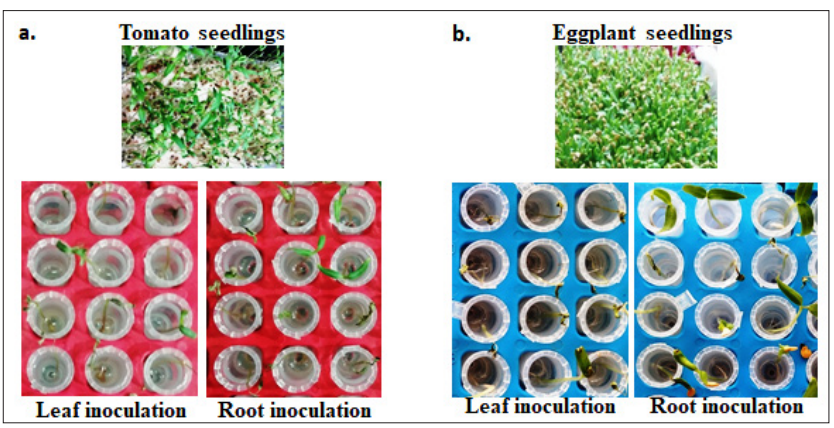

Figure 1: $R$. solanacearum pathogenicity in tomato and eggplant seedlings.

a) Tomato seedlings is used as a host to study virulence of $R$. solanacearum by both leaf and root inoculations.

b) Eggplant seedlings used as a host to study virulence of $R$. solanacearum by both leaf and root inoculations.

\section{Discussion}

Seedlings as model to study $R$. solanacearum virulence have several unique advantages. First, in both leaf [12] and root inoculation [14] studies, the seedlings are kept in sterile water which ensures minimal interaction with other micro-organisms. This has facilitated to study $R$. solanacearum infection under gnotobiotic condition $[12-14,18]$. It is evident that $R$. solanacearum infects and cause disease in seedlings without addition of some other bacteria from external sources such as soil. Secondly, the pathogen localization and disease progress in seedlings. Due to small size, the entire seedling could be stained at regular intervals after the infection. By gus staining, it is observed that $R$. solanacearum colonizes the shoot apical region of the seedlings within $24 \mathrm{~h}$ of inoculation either in root or in the leaf [15]. This provides explanation for two important observations i.e.

(i) The initiation of the disease from the apical region,

(ii) Why the disease magnitude is higher by leaf inoculation than by root inoculation [15].

This finding has given a new insight to the disease mechanism. Thirdly, virulence comparison of $R$. solanacearum in different hosts. One of the difficulties to study $R$. solanacearum different hosts is the disease reproducibility. There are instances when the pathogen can live inside susceptible host without causing disease. The reason for this mysterious behavior of the pathogen is not known. This may a feature of the pathogen because of its ability to do systemic infection in the host plant. Considering it, infection in seedlings has a greater chance of disease reproducibility than grown up plants. It is evident that under the same condition of infection, $R$. solanacearum is more aggressive eggplant seedlings than tomato seedlings. $R$. solanacearum mutants deficient in the same virulence factor exhibit significance difference with regard to their virulence between the two hosts. Apart from the above advantages, the small size and cost efficiency of the seedlings allows to perform largescale screening of virulence deficient mutants [15].

\section{Conclusion}

Seedlings can serve as a potential model for studying virulence of a pathogen in a gnotobiotic condition. The reproducibility, low cost and the short duration for getting results ensure its utility in many host-pathogen interaction studies. It is a promising system to understand the mechanisms underlying the pathogenicity and host adaptability.

\section{Acknowledgement}

KK is grateful to UGC, GoI for the NET-JRF fellowship. SKR laboratory is supported by twinning, UExcel NER grants from DBT, GoI, Departmental grants such as UGC-SAP (DRSII), DST FIST.

\section{Conflict of Interest}

The authors declare that the research was conducted in the absence of any commercial or financial relationships that could be construed as a potential conflict of interest.

\section{References}

1. Hayward AC (1991) Biology and epidemiology of bacterial wilt caused by Pseudomonas solanacearum. Annual Rev Phytopathol 29: 65-87.

2. Genin S (2010) Molecular traits controlling host range and adaptation to plants in Ralstonia solanacearum. New Phytol 187(4): 920-928.

3. Shiomi T, Mulya K, Oniki M (1989) Bacterial wilt of cashew (Anacardium occidentale) caused by Pseudomonas solanacearum in Indonesia. Ind Crops Res J 2: 29-35.

4. Mayers PE, Hutton DG (1987) Bacterial wilt, a new disease of custard apple: symptoms and etiology. Annals of App Biol 111(1): 135-141.

5. Elphinstone JG (2005) The current bacterial wilt situation: a global overview. In: Allen C, Prior P, Hayward AC (Eds.), Bacterial wilt disease and the Ralstonia solanacearum species complex. St. Paul, MN, APS Press, USA, pp. 9-28.

6. Dianese JC, Dristig MCG, Criiz AP (1990) Susceptibility to wilt associated with Pseudotnonas solanacearum among six species of Eucalyptus growing in equatorial Brazil. Austalasian Plant Pathol 19: 71-76.

7. Mansfield J, Genin S, Magori S, Citovsky V, Sriariyanum M, et al. (2012) Top 10 plant pathogenic bacteria in molecular plant pathology. Mol Plant Pathol 13(6): 614-629.

8. Schell MA (2000) Control of virulence and pathogenicity genes of Ralstonia solanacearum by an elaborate sensory network. Annual Rev Phytopathol 38: 263-292.

9. Genin S, Denny TP (2012) Pathogenomics of the Ralstonia solanacearum species complex. Annual Rev Phytopathol 50: 67-89.

10. Perrier A, Peyraud R, Rengel D, Barlet X, Lucasson E, et al. (2016) Enhanced in planta fitness through adaptive mutations in EfpR, a dual regulator of virulence and metabolic functions in the plant pathogen Ralstonia solanacearum. PLoS Pathog 12(12): e1006044. 
11. Huet G (2014) Breeding for resistances to Ralstonia solanacearum. Frontiers in Plant Sc 5: 715.

12. Kumar R, Barman A, Phukan T, Kabyashree K, Singh N, et al. (2017) Ralstonia solanacearum virulence in tomato seedlings inoculated by leaf clipping. Plant Pathol 66(5): 835-841.

13. Phukan T, Kabyashree K, Singh R, Sharma PL, Singh N, et al. (2019) Ralstonia solanacearum virulence in eggplant seedlings by the leaf clip inoculation. Phytopathol Research 1: 23.

14. Singh N, Phukan T, Sharma PL, Kabyashree K, Barman A, et al. (2018) An innovative root inoculation method to study Ralstonia solanacearum pathogenicity in tomato seedlings. Phytopathology 108(4): 436-442.

15. Kabyashree K, Kumar R, Sen P, Satapathy SS, Ray SK (2020) Ralstonia solanacearum preferential colonization in the shoot apical meristem explains its pathogenicity pattern in tomato seedlings. Plant Pathol 69(7): 1347-1356.

16. Ling L, Han X, Li X, Zhang X, Wang H, et al. (2020) A Streptomyces sp. NEAU-HV9: Isolation, identification, and potential as a biocontrol agent against Ralstonia solanacearum of tomato plants. Microorganisms 8(3): 351.

17. Agarwal H, Dowarah B, Baruah PM, Bordoloi KS, Krishnatreya DB, et al. (2020) Endophytes from Gnetum gnemon L can protect seedlings against infection of the phytopathogenic bacterium $R$. solanacearum as well as promote plant growth in tomato. Microbiol Research 238: 126503.

18. Planas Marquès M, Kressin JP, Kashyap A, Panthee DR, Louws FJ, et al. (2020) Four bottlenecks restrict colonization and invasion by the pathogen Ralstonia solanacearum in resistant tomato. J Expt Bot 71(6): 2157-2171.

For possible submissions Click below: 